\title{
Hyperchaos in coupled Colpitts oscillators
}

\author{
Cenys, Antanas; Tamasevicius, Arunas; Baziliauskas, Antanas; Krivickas, Romanas; Lindberg, Erik
}

\section{Published in:}

Chaos, Solitons \& Fractals

Publication date:

2003

Document Version

Publisher's PDF, also known as Version of record

Link back to DTU Orbit

Citation $(A P A)$ :

Cenys, A., Tamasevicius, A., Baziliauskas, A., Krivickas, R., \& Lindberg, E. (2003). Hyperchaos in coupled Colpitts oscillators. Chaos, Solitons \& Fractals, 17(2-3), 349-353. http://dads.dtv.dk.globalproxy.cvt.dk:2048/cgibin/fulltext/elsevier/ohm03480/09600779/v0017i02/02003739/main.pdf

\section{General rights}

Copyright and moral rights for the publications made accessible in the public portal are retained by the authors and/or other copyright owners and it is a condition of accessing publications that users recognise and abide by the legal requirements associated with these rights.

- Users may download and print one copy of any publication from the public portal for the purpose of private study or research.

- You may not further distribute the material or use it for any profit-making activity or commercial gain

- You may freely distribute the URL identifying the publication in the public portal

If you believe that this document breaches copyright please contact us providing details, and we will remove access to the work immediately and investigate your claim 


\title{
Hyperchaos in coupled Colpitts oscillators
}

\author{
Antanas Čenys ${ }^{a}$, Arūnas Tamaševičius ${ }^{\text {a,* }}$, Antanas Baziliauskas ${ }^{b}$, \\ Romanas Krivickas ${ }^{\mathrm{b}}$, Erik Lindberg ${ }^{\mathrm{c}}$ \\ ${ }^{a}$ Semiconductor Physics Institute, A. Goštauto 11, Vilnius LT-2600, Lithuania \\ ${ }^{\mathrm{b}}$ Department of Theoretical Radioengineering, Faculty of Telecommunications and Electronics, Kaunas University of Technology, \\ Student 50, Kaunas LT-3031, Lithuania \\ c Ørsted DTU Department, Technical University of Denmark, Ørsted Plads 349, Lyngby DK-2800, Denmark
}

\begin{abstract}
The paper suggests a simple solution of building a hyperchaotic oscillator. Two chaotic Colpitts oscillators, either identical or non-identical ones are coupled by means of two linear resistors $R_{k}$. The hyperchaotic output signal $v(t)$ is a linear combination, specifically the mean of the individual chaotic signals, $v(t)=\left(v_{1}+v_{2}\right) / 2$. The corresponding differential equations have been derived. The results of both, numerical simulations and hardware experiments are presented. The coupling coefficient $k \propto 1 / R_{k}$ should be small to avoid mutual synchronisation of the individual oscillators. The spectrum of the Lyapunov exponents (LE) have been calculated versus the coefficient $k$. For weakly coupled oscillators there are two positive LE indicating hyperchaotic behaviour of the overall system.

(c) 2002 Elsevier Science Ltd. All rights reserved.
\end{abstract}

\section{Introduction}

The classical Colpitts oscillator with special parameter settings exhibits chaotic behaviour [1,2], thus can be used to generate noise-like broadband signals. The oscillator is very flexible - the fundamental frequency can be tuned from several kilohertz to several gigahertz, i.e. to the microwave range. The complexity of chaotic oscillations is characterized by the number of positive Lyapunov exponents (LE), i.e. the number of directions in the phase space along which the phase trajectories are unstable. Chaotic Colpitts oscillator has only one positive LE. Meanwhile for chaos based communications more complicated oscillators, characterized by multiple positive LE are needed [3,4]. Dynamical systems having more than one positive LE are called hyperchaotic ones.

The first hyperchaotic electronic circuit has been suggested by Matsumoto et al. [5]. During the past five years a large number of various hyperchaotic oscillators have been proposed by several authors, e.g. [6-25]. Among them are the fourth and higher order circuits composed of non-linearly coupled second order linear oscillators [6,7,10,12,13,15], high-order high-pass filter based oscillators [11,14], the sixth and higher order arrays of coupled third order non-linear chaotic oscillators [16-19], also the so-called "infinite" dimensional, delay line based oscillators [22-25], operating at kilohertz frequencies [22,23], as well as in the microwave range [24,25]. Some of the early hyperchaotic oscillators are described in the review papers [8,9]. Possible applications of hyperchaotic circuits to communications, specifically to secure communications are discussed and illustrated in [17,18,20,21].

In the present paper we suggest a simple solution of building a hyperchaotic Colpitts circuit. Two chaotic Colpitts oscillators, either identical or non-identical ones are coupled by means of linear resistors. The output hyperchaotic signal is a linear combination, specifically the mean of the individual chaotic signals.

\footnotetext{
${ }^{*}$ Corresponding author.
} 

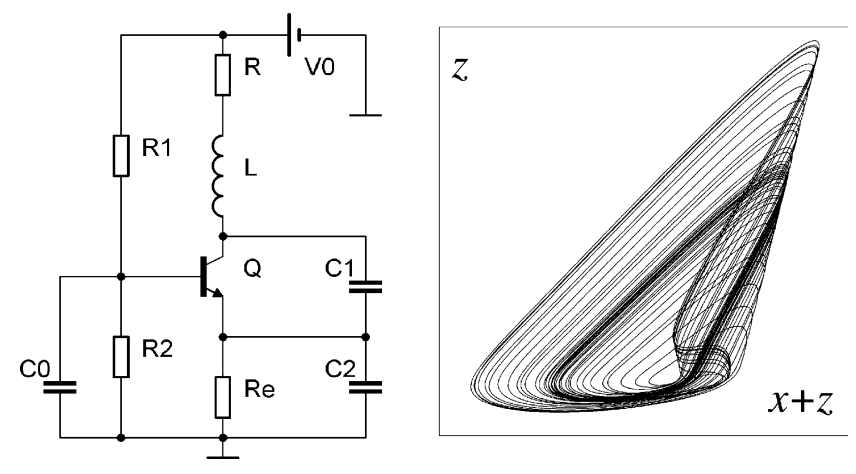

Fig. 1. The Colpitts oscillator: circuit diagram (left) and phase portrait (right). $\varepsilon=1, a=30, b=0.8, c=20, d=0.08, e=10$.
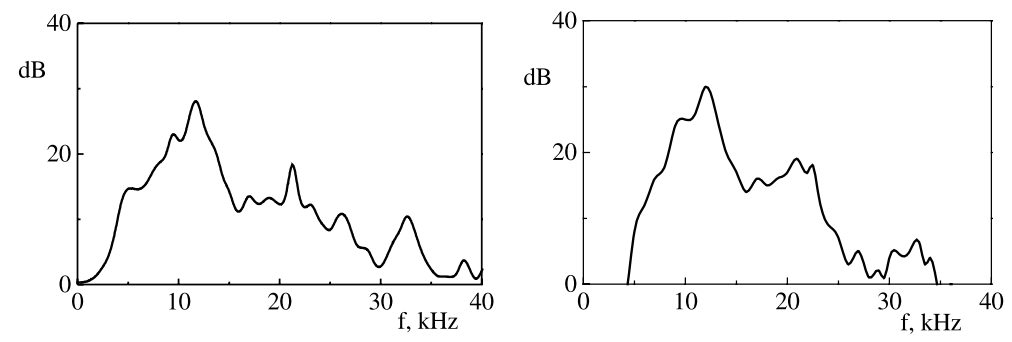

Fig. 2. Power spectra from the Colpitts oscillator: numerical (left) and experimental (right). $\varepsilon=1, a=30, b=0.8, c=20, d=0.08$, $e=10, \mathrm{Q}-2 \mathrm{~N} 3904, L=850 \mu \mathrm{H}, C_{1}=C_{2}=470 \mathrm{nF}, C_{0}=47 \mu \mathrm{F}, R=36 \Omega, R_{e}=510 \Omega, R_{1}=R_{2}=3 \mathrm{k} \Omega, V_{0}=15 \mathrm{~V}$.

\section{Chaotic Colpitts oscillator}

Dynamics of the Colpitts oscillator (Fig. 1, left) can be described by the following differential equations:

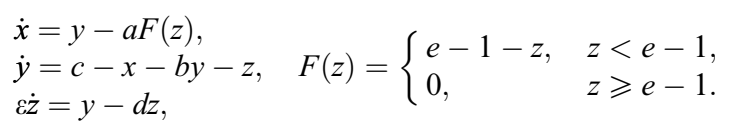

Here

$$
\begin{aligned}
& x=\frac{V_{C 1}}{V^{*}}, \quad y=\frac{\rho I_{L}}{V^{*}}, \quad z=\frac{V_{C 2}}{V^{*}}, \quad \vartheta=\frac{t}{\tau}, \quad \dot{u} \equiv \frac{\mathrm{d} u}{\mathrm{~d} \vartheta}, \quad \rho=\sqrt{\frac{L}{C_{1}}}, \quad \tau=\sqrt{L C_{1}}, \quad \varepsilon=\frac{C_{2}}{C_{1}}, \quad a=\frac{\rho}{r}, \\
& b=\frac{R}{\rho}, \quad c=\frac{V_{0}}{V *}, \quad d=\frac{\rho}{R_{e}}, \quad e=\frac{R_{2}}{R_{1}+R_{2}} c .
\end{aligned}
$$

Typical phase portrait is presented in Fig. 1 (right), while power spectra are illustrated in Fig. 2.

\section{Coupled Colpitts oscillators}

Two Colpitts oscillators, Colp1 and Colp2, specifically the collector nodes, are coupled to each other by two linear resistors $R_{k}$ (Fig. 3). The output signal $v(t)$ is simply the mean of the collector voltages $\left(x_{i}+z_{i}\right)$ of the individual oscillators:

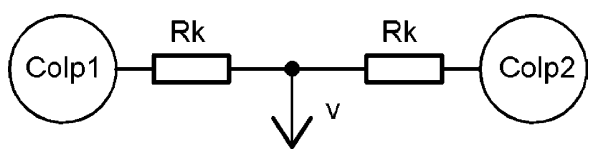

Fig. 3. Two coupled Colpitts oscillators. 


$$
v=\frac{\left(x_{1}+z_{1}\right)+\left(x_{2}+z_{2}\right)}{2} .
$$

The coupled system is given by

$$
\begin{aligned}
& \dot{x}_{1}=\left[y_{1}-a F\left(z_{1}\right)+k\left(v-x_{1}-z_{1}\right)\right] \omega_{1}, \quad \dot{x}_{2}=\left[y_{2}-a F\left(z_{2}\right)+k\left(v-x_{2}-z_{2}\right)\right] \omega_{2}, \\
& \dot{y}_{1}=\left[c-x_{1}-b y_{1}-z_{1}\right] \omega_{1}, \quad \dot{y}_{2}=\left[c-x_{2}-b y_{2}-z_{2}\right] \omega_{2}, \quad \varepsilon \dot{z}_{1}=\left[y_{1}-d z_{1}+k\left(v-x_{1}-z_{1}\right)\right] \omega_{1}, \\
& \varepsilon \dot{z}_{2}=\left[y_{2}-d z_{2}+k\left(v-x_{2}-z_{2}\right)\right] \omega_{2} .
\end{aligned}
$$

Here $k=\rho / R_{k}$ is the coupling coefficient, $\omega_{1}$ and $\omega_{2}$ are the reduced cyclic frequencies of the oscillators.

\subsection{Identical oscillators}

The phase portraits of the system composed of identical oscillators $\left(\omega_{1}=\omega_{2}\right)$ are shown in Fig. 4 . Experimentally observed phase portraits correspond very well to the numerical ones.

The fine diagonal in Fig. 4d indicates full synchronisation of the individual oscillators at larger coupling coefficients. Obviously, the system of synchronized chaotic oscillators is not a hyperchaotic one. Visual inspection of the phase portraits at smaller coupling coefficients does not allow one to distinguish between simple chaotic and hyperchaotic states. This can be done by direct calculation of the LE (Fig. 5). At $k=0$ there are two positive LE, as expected. Meanwhile at $k>0$ the situation is rather complicated. There are certain parameter windows (Fig. 5, right) where the oscillations are either weakly chaotic $(k \approx 0.02$; low value single positive LE) or even periodic $(k \approx 0.03$; the largest LE is zero!).

\subsection{Non-identical oscillators}

The system of non-identical oscillators $\left(\omega_{1} \neq \omega_{2}\right)$ has an advantage in the sense, that full synchronisation is impossible in this case. Moreover, no chaotic and periodic windows have been detected at small coupling coefficients (Fig. 6). The systems remains hyperchaotic with two positive LE up to $k=0.12$.

In addition, it is worth to note, that weak coupling of non-identical oscillators, e.g. $k=0.05$ enables one to reduce the unevenness of the power spectrum (Fig. 7, middle).

The hardware experiments do confirm the numerical result of smoothing the power spectra by means of weak coupling of the oscillators (Fig. 8, middle).

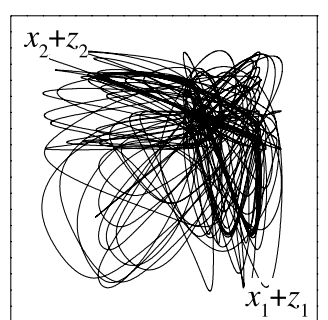

(a)

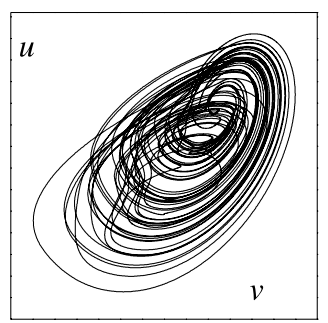

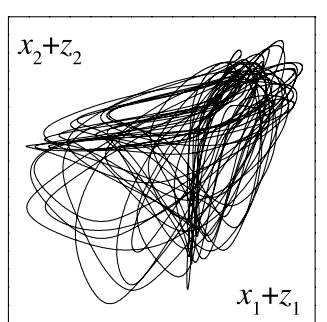

(b)

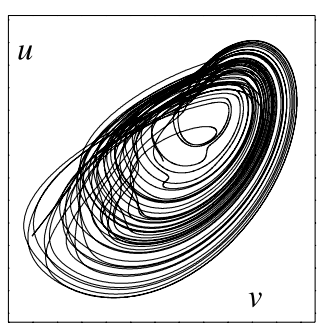

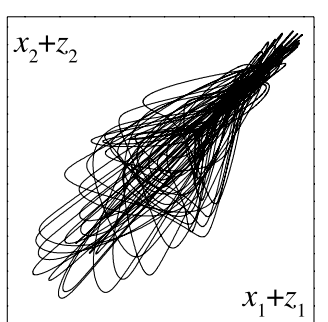

(c)

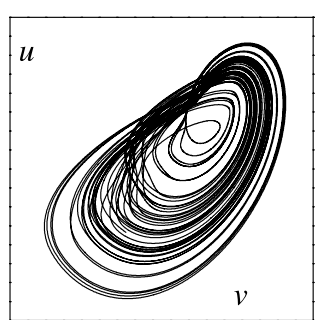

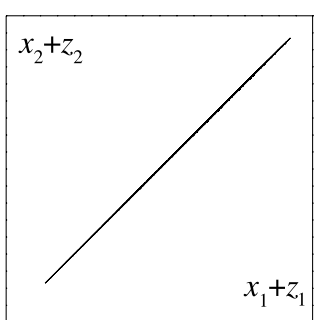

(d)

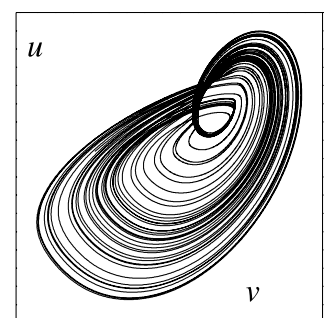

Fig. 4. Phase portraits of two coupled identical Colpitts oscillators at different coupling coefficients: (a) $k=0$, (b) $k=0.1$, (c) $k=0.3$, (d) $k=1.0$. In the top row the $x_{1}+z_{1}$ and $x_{2}+z_{2}$ is proportional to the collector voltage of the Colp1 and the Colp2 oscillator, respectively. In the bottom row the $v$ is the mean collector voltage given by Eq. (3) and $u$ is simulated from an auxiliary linear differential equation: $\dot{u}=v-u$. 

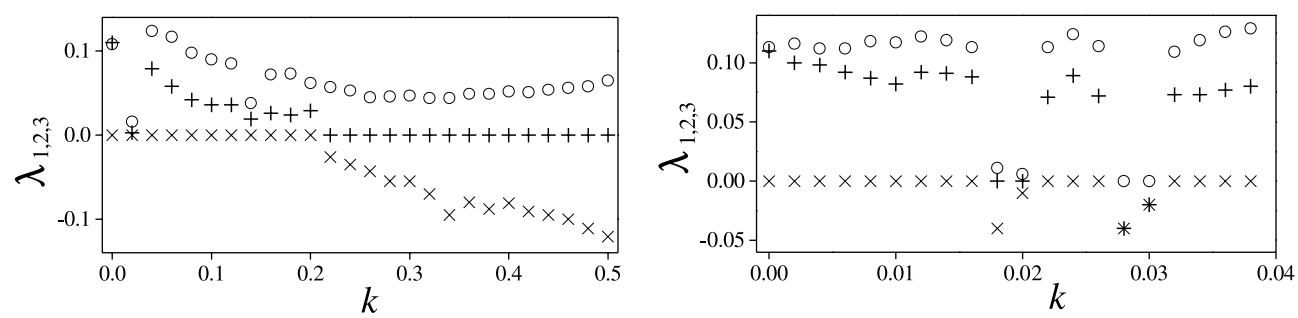

Fig. 5. Three largest LE, $\lambda_{1}, \lambda_{2}, \lambda_{3}$ from Eqs. (3) and (4). Panorama view (left), detailed view (right). Identical oscillators, $w_{1}=w_{2}=1$, $\varepsilon=1, a=30, b=0.8, c=20, d=0.08, e=10$.
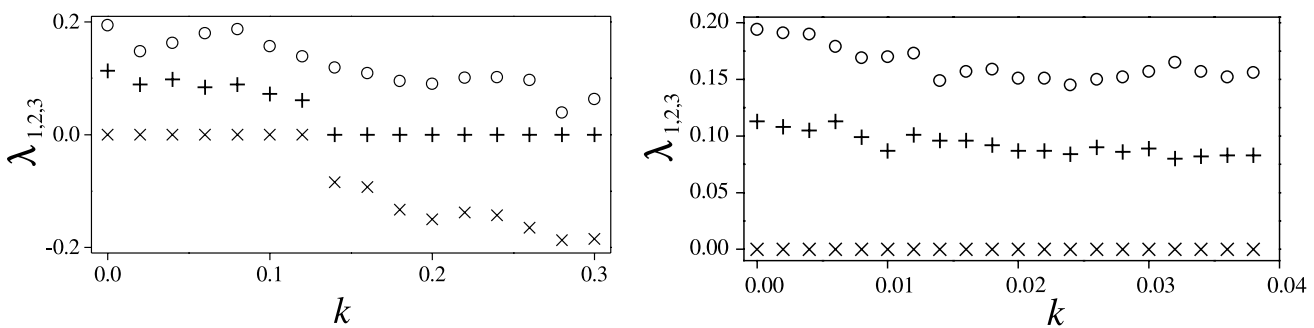

Fig. 6. Three largest LE, $\lambda_{1}, \lambda_{2}, \lambda_{3}$ from Eqs. (3) and (4). Panorama view (left), detailed view (right). Non-identical oscillators, $w_{1}=1$, $w_{2}=1.6, \varepsilon=1, a=30, b=0.8, c=20, d=0.08, e=10$.
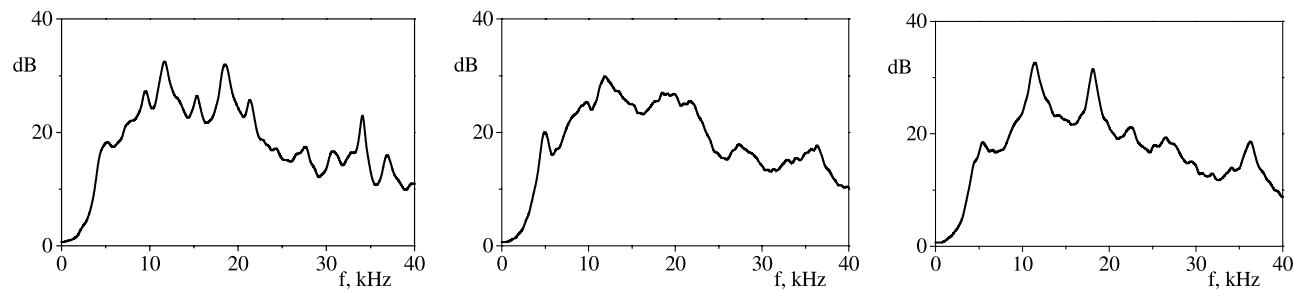

Fig. 7. Power spectra of non-identical oscillators $\left(w_{1}=1, w_{2}=1.6\right)$ at different coupling coefficients: $k=0$ (left), $k=0.05$ (middle), $k=0.1$ (right). $\varepsilon=1, a=30, b=0.8, c=20, d=0.08, e=10$.
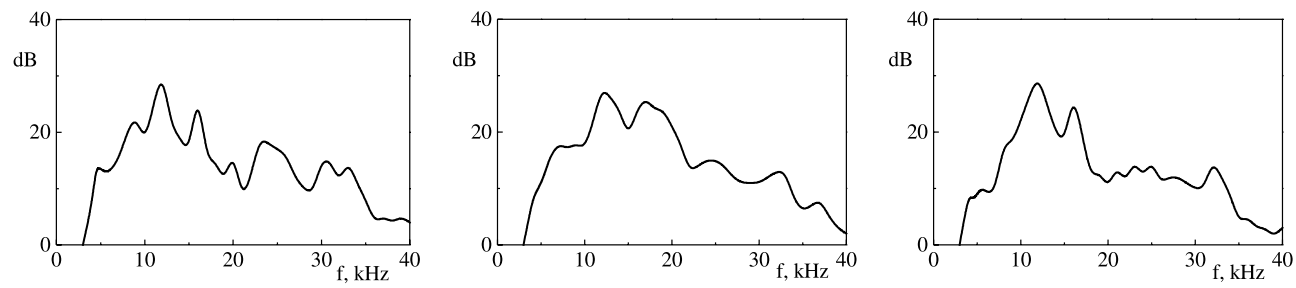

Fig. 8. Experimental power spectra of non-identical oscillators $\left(f_{1} \approx 11 \mathrm{kHz}, f_{2} \approx 17 \mathrm{kHz}\right)$ at different coupling resistors: $R_{k}=5.1 \mathrm{k} \Omega$ (left), $R_{k}=1.1 \mathrm{k} \Omega$ (middle), $R_{k}=750 \Omega$ (right). Q $-2 \mathrm{~N} 3904, C_{0}=47 \mu \mathrm{F}, R=36 \Omega, R_{e}=510 \Omega, R_{1}=R_{2}=3 \mathrm{k} \Omega, V_{0}=15 \mathrm{~V}$. The $L C$ tank parameters are as follows: $L=850 \mu \mathrm{H}, C_{1}=C_{2}=470 \mathrm{nF}$ (in Colp1) and $L=530 \mu \mathrm{H}, C_{1}=C_{2}=300 \mathrm{nF}$ (in Colp2).

\section{Conclusions}

Two weakly coupled Colpitts oscillators exhibit hyperchaotic behaviour characterized by two positive LE. In the case of identical oscillators there are undesirable regions of coupling coefficient where weakly chaotic (small single LE) and even periodic oscillations are observed. Meanwhile, non-identical Colpitts oscillators with different fundamental frequencies have an advantage. The system oscillates hyperchaotically over sufficiently wide range of coupling without 
any chaotic or periodic windows. In addition, certain carefully chosen coupling of non-identical oscillators provide relatively smooth power spectrum of the overall system. We expect that coupling of a larger number of chaotic Colpitts oscillators can produce hyperchaotic systems with multiple positive LE and rather smooth power spectra.

\section{Acknowledgements}

A. Čenys and A. Tamaševičius were supported in part by NATO under the contract no. PST.CLG977018.

\section{References}

[1] Kennedy MP. Chaos in the Colpitts oscillator. IEEE Trans Circuits Syst-I 1994;41:771-4.

[2] Maggio GN, De Feo O, Kennedy MP. Nonlinear analysis of the Colpitts oscillator and applications to design. IEEE Trans Circuits Syst-I 1999;46:1118-30.

[3] Peng JH, Ding EJ, Ding M, Yang W. Synchronizing hyperchaos with a scalar transmitted signal. Phys Rev Lett 1996;76:904-7.

[4] Tamaševičius A, Čenys A. Synchronizing hyperchaos with a single variable. Phys Rev E 1997;55:297-9.

[5] Matsumoto T, Chua LO, Kobayashi K. Hyperchaos: laboratory experiment and numerical confirmation. IEEE Trans Circuits Syst-I 1986;33:1143-7.

[6] Tamaševičius A, Namajūnas A, Čenys A. Simple 4D chaotic oscillator. Electron Lett 1996;32:957-8.

[7] Tamaševičius A, Čenys A, Mykolaitis G, Namajūnas A, Lindberg E. Hyperchaotic oscillator with gyrators. Electron Lett 1997;33:542-4.

[8] Tamaševičius A. Hyperchaotic circuits: state of the art. In: Proc. 5th Int. Workshop on Nonlinear Dynamics of Electronic Systems NDES'97, Moscow, Russia, 1997. p. 97-102.

[9] Tamaševičius A, Čenys A, Namajūnas A, Mykolaitis G, Lindberg E. Synchronizing hyperchaotic circuits. In: Applied nonlinear dynamics and stochastic systems near the millenium. In: AIP Conf. Proc., vol. 411. American Institute of Physics: New York, 1997. p. 81-6.

[10] Tamaševičius A, Čenys A. Hyperchaos in dynamical systems with a mono-active degree of freedom. Chaos, Solitons \& Fractals 1998;9:115-9.

[11] Lindberg E, Tamaševičius A, Čenys A, Mykolaitis G, Namajūnas A, Hyperchaos via $\chi$-diode. In: Proc. 6th Int. Workshop on Nonlinear Dynamics of Electronic Systems NDES'98, Budapest, Hungary, 1998. p. 125-8.

[12] Tamaševičius A, Čenys A, Mykolaitis G, Hyperchaos in a system of nonlinearly coupled linear oscillators. In: Proc. Int. Symp. on Nonlinear Theory and its Applications NOLTA'98, vol. 2. Crans-Montana: Switzerland, 1998. p. 611-4.

[13] Murali K, Tamaševičius A, Mykolaitis G, Namajūnas A, Lindberg E, Unstable oscillators based hyperchaotic circuit. In: Proc. 7th Int. Workshop on Nonlinear Dynamics of Electronic Systems NDES'99, Rønne, Denmark, 1999. p. 241-4.

[14] Čenys A, Tamaševičius A, Mykolaitis G, Namajūnas A. Hyperchaos with high metric entropy. Nonlinear Phenom Complex Syst 1999;2:36-40.

[15] Murali K, Tamaševičius A, Mykolaitis G, Namajūnas A, Lindberg E. Hyperchaotic system with unstable oscillators. Nonlinear Phenom Complex Syst 2000;3:7-10.

[16] Anishchenko VS, Vadivasova TE, Astakhov VV, Sosnovtseva OV, Wu CW, Chua LO. Dynamics of two coupled Chua's circuits. Int J Bifurcat Chaos 1995;5:1677-99.

[17] Kocarev L, Parlitz U. General approach for chaotic synchronization with application to communication. Phys Rev Lett 1995;74:5028-31.

[18] Kocarev L, Parlitz U, Stojanovski T. An application of synchronized chaotic dynamic arrays. Phys Lett A 1996;217:280-4.

[19] Čenys A, Tamaševičius A, Mykolaitis G, Hyperchaos and synchronization in mean field coupled chaotic oscillators. In: Proc. Int. Symp. on Nonlinear Theory and its Applications NOLTA'98, vol. 2. Crans-Montana: Switzerland, 1998. p. 519-22.

[20] Brucoli M, Cafagna D, Carnimeo L, Grassi G. Synchronization of hyperchaotic circuits via continuous feedback control with application to secure communications. Int J Bifurcat Chaos 1998;8:2031-40.

[21] Brucoli M, Cafagna D, Carnimeo L, Hyperchaotic synchronization of coupled Chua's oscillators via a scalar signal. In: Proc. 7th Int. Workshop on Nonlinear Dynamics of Electronic Systems NDES'99, Rønne, Denmark, 1999. p. 285-8; A hyperchaotic cryptosystem based on the synchronization of two coupled Chua's oscillators via a scalar signal. In: Proc. 8th Int. Workshop NDES'2000, Catania, Italy, 2000. p. 71-5.

[22] Namajūnas A, Pyragas K, Tamaševičius A. An electronic analog of the Mackey-Glass system. Phys Lett A 1995;201:42-6.

[23] Tamaševičius A, Čenys A, Namajūnas A, Mykolaitis G. Synchronizing hyperchaos in infinite-dimensional dynamical systems. Chaos, Solitons \& Fractals 1998;9:1403-8.

[24] Čenys A, Lindberg E, Anagnostopoulos AN, Mykolaitis G, Tamaševičius A, Broadband hyperchaotic oscillator with delay line. In: AIP Conf. Proc., vol. 622, American Institute of Physics, Melville, New York, 2002, p. 39-45.

[25] Mykolaitis G, Tamaševičius A, Čenys A, Bumelienè S, Anagnostopoulos AN, Kalkan N, Very high and ultrahigh frequency hyperchaotic oscillators with delay line. Chaos, Solitons \& Fractals 2003;17:this issue. 


\section{View of one Document}

Title Hyperchaos in coupled Colpitts oscillators

Author Cenys, A.; Tamasevicius, A.; Baziliauskas, A.; Krivickas, R.; Lindberg, E.

Abstract The paper suggests a simple solution of building a hyperchaotic oscillator. Two chaotic Colpitts oscillators, either identical or non-identical ones are coupled by means of two linear resistors $R " k$. The hyperchaotic output signal $v(t)$ is a linear combination, specifically the mean of the individual chaotic signals,

$v(t)=\left(v^{\prime \prime} 1+v^{\prime \prime} 2\right) / 2$. The corresponding differential equations have been derived. The results of both, numerical simulations and hardware experiments are presented. The coupling coefficient k@?1/R"k should be small to avoid mutual synchronisation of the individual oscillators. The spectrum of the Lyapunov exponents (LE) have been calculated versus the coefficient k. For weakly coupled oscillators there are two positive LE indicating hyperchaotic behaviour of the overall system.

\section{Journal Chaos, Solitons and Fractals}

Title

I ssue Vol.17 Issue.2-3

Page no. 349-353

Provider elsevier

Publication 2003

Date

I SSN 09600779

Doc. type journal article 